BIBLIOGRAFIA 



\section{A conexão holandesa}

\section{Luís Felipe Sobral ${ }^{1}$}

Resenha de: FRANÇOZO, Mariana de Campos. De Olinda a Holanda. O gabinete de curiosidades de Nassau. Campinas: Editora da Unicamp, 2014, 287 pp., 44 ils.
1. Pós-doutorando em Antropologia Social na Universidade de São Paulo e bolsista da Fapesp. Email: <lf_sobral@ yahoo.com>. 
2. Ver Alfred Métraux (1988, p. 95-110).

3. Frank Lestringant discordou recentemente dessa conjectura, focando-se para tanto no tacape tupinambá do Trocadéro, que Métraux também remonta a Thevet, mas incluindo igualmente em sua discordância essa trajetória proposta do manto. Cf. Frank Lestringant (2004, p. 214-216, nota 29).
No terceiro número do boletim do Museu de Etnografia do Trocadéro, publicado em janeiro de 1932, encontra-se um artigo do antropólogo suíço Alfred Métraux, no qual ele procura rastrear a procedência de dois objetos do museu, que atribui aos tupinambás: um manto de plumas e um tacape ${ }^{2}$. Segundo ele, esses foram provavelmente os primeiros objetos do Novo Mundo que chegaram à França e talvez também os integrantes da coleção inicial do Trocadéro. No entanto, o antigo catálogo do museu não diz nada com precisão a respeito deles, daí o esforço de investigar suas origens. Considerando a centralidade epistemológica da qual gozava o objeto etnográfico, e portanto também o museu, no processo de emergência da etnologia francesa no entreguerras, tal esforço era de fato imprescindível.

A atribuição do manto de plumas aos tupinambás pautou-se em um exercício de duplo cotejamento entre o exemplar do Trocadéro e os de outros museus etnográficos europeus, cujas informações sobre suas procedências diversas eram um pouco mais precisas e com os quais aquele guardava uma semelhança inegável, de um lado; e de outro, os relatos dos autores antigos, viajantes e missionários que descreveram o manto em detalhes. Quanto à trajetória específica desse objeto dos tupinambás ao Trocadéro, as fontes não permitiram que Métraux propusesse senão uma conjectura, pautada em dois textos do frade franciscano André Thevet, cronista da empreitada francesa que procurou estabelecer no século XVI uma colônia no Brasil, a chamada França Antártica. Thevet teria adquirido o manto em 1555 na baía do Rio de Janeiro; subsequentemente - não se sabe exatamente quando -, ele o teria dado de presente a Jean de Bertrandy, antes ou durante o cardinalato deste, que por sua vez o teria depositado no gabinete de curiosidades real, cuja guarda cabia ao próprio Thevet. De lá, o objeto teria sido sucessivamente transferido ao gabinete de medalhas, ao Louvre e, enfim, ao Trocadéro. Os antigos inventários do gabinete de medalhas não mencionam todavia o manto, observa Métraux. Sua conjectura alimenta-se em grande medida da presença de uma diadema de contas de vidro no capuz, um indício de que o manto teria sido produzido por um grupo em contato antigo com os europeus, justamente o caso dos tupinambás da baía do Rio de Janeiro ${ }^{3}$.

Métraux empenha-se fundamentalmente em propor uma trajetória plausível ao manto. As informações apresentadas aí são mobilizadas no intuito estrito de rastrear com acuidade cada etapa desse percurso, desconsiderando-se tudo o que se afasta dessa finalidade. Todavia, essa trajetória é na verdade muito mais complexa, ultrapassando os limites estreitos do deslocamento espacial; ela inclui, por exemplo, tanto os motivos que suscitaram o interesse europeu por esse tipo de objeto, como aqueles que franquearam um circuito de trocas materiais e simbólicas entre a colônia e a metrópole. $\bigcirc$ próprio artigo suscita, aqui e ali, diversas questões que sugerem essa complexidade, mas que permanecem sem respostas precisas: por que e como Thevet teria obtido o manto? por que ele o teria dado a Jean de Bertrandy? por que Bertrandy o teria depositado no gabinete de 
curiosidades real? o que teria provocado sua transferência desse gabinete ao de medalhas e assim por diante até o Trocadéro?

Ainda que as questões suscitadas pelo artigo de Métraux, além de muitas outras similares advindas do esforço de rastrear a procedência de objetos abrigados em coleções etnográficas, careçam rigorosamente de respostas específicas, elas são iluminadas pelo livro de Mariana de Campos Françozo, produto de uma tese de doutorado em ciências sociais orientada, na Unicamp, por John Monteiro. A autora, atualmente professora de estudos museológicos na Faculdade de Arqueologia da Universidade de Leiden, Holanda, e pesquisadora associada do Museu Nacional de Etnologia da Holanda, debruça-se aí sobre o processo de formação, exibição e dispersão da coleção etnográfica reunida pelo conde João Maurício de Nassau-Siegen no período em que foi governador do Brasil Holandês, entre 1637 e 1644. O interesse da autora pela cultura material, observa Heloisa Pontes na apresentação do livro, já estava presente em seu mestrado, dedicado ao período de Sérgio Buarque de Holanda no Museu Paulista, quando ele emprestou tal conceito da etnologia alemã oitocentista para argumentar, contra ela própria, que o contato entre nativos e europeus não teve um efeito destrutivo, mas construtivo ${ }^{4}$. Agora se trata de mostrar que o entendimento pleno da circulação transatlântica de objetos e saberes no período colonial, representada aqui pela coleção de Nassau, passa necessariamente pelo escrutínio das relações sociais e políticas que tornaram possível tal circulação, seja na América, entre nativos e europeus, ou na Europa, entre os próprios europeus. É esse esforço minucioso que ilumina justamente as respostas das quais carece o artigo de Métraux.

Entre os objetos que formavam a coleção, encontra-se um manto de plumas tupinambá, que se supõe, apesar de algumas dúvidas, ser o mesmo alojado atualmente no Museu Nacional da Dinamarca. Esse exemplar serviu justamente ao exercício de cotejamento com o do Trocadéro realizado por Métraux em seu artigo $^{5}$. $\bigcirc$ manto é mencionado já na introdução do livro, na qual a autora conduz o leitor em uma visita pelo Museu do Castelo de Wasserburg-Anholt, em Isselburg, Alemanha. Dentre os inúmeros retratos dos membros da família Salm-Salm, proprietária do castelo, e de seus parentes e aliados que preenchem as paredes da Grande Sala, ou Sala dos Cavaleiros (Rittersaal), um deles destaca-se entre as poses sóbrias e elegantes (Figura 1):

Logo no primeiro conjunto de quadros, na parede leste, cujas janelas oferecem a vista do jardim, observa-se uma jovem dama posando com vestido de cetim branco, um colar de pérolas e um manto de penas vermelhas e amarelas preso por um broche na altura de seu ombro esquerdo. Na cabeça, usa um ornamento também feito de penas vermelhas. Na mão direita, a jovem leva uma lança; atrás dela, há uma paisagem tropical com coqueiros ${ }^{6}$.

Essa jovem é a princesa Sofia do Palatinado, retratada por sua irmã, Louise Hollandine do Palatinado, ambas filhas de Frederico V, eleitor palatino, e Elizabeth Stuart. Os retratos de damas da corte fantasiadas não eram certamente
4. Ver Mariana de Campos Françozo (2004).

5. Ver Métraux (1988, p. 6). Manto de plumas vermelhas, $120 \mathrm{~cm}$, inv. n. H.5.931, Museu Nacional da Dinamarca, Coleções Etnográficas, ver Mariana de Campos Françozo (2014, p. 285, fig. 40).

6. Cf. Mariana de Campos Françozo (2014, p. 26). 


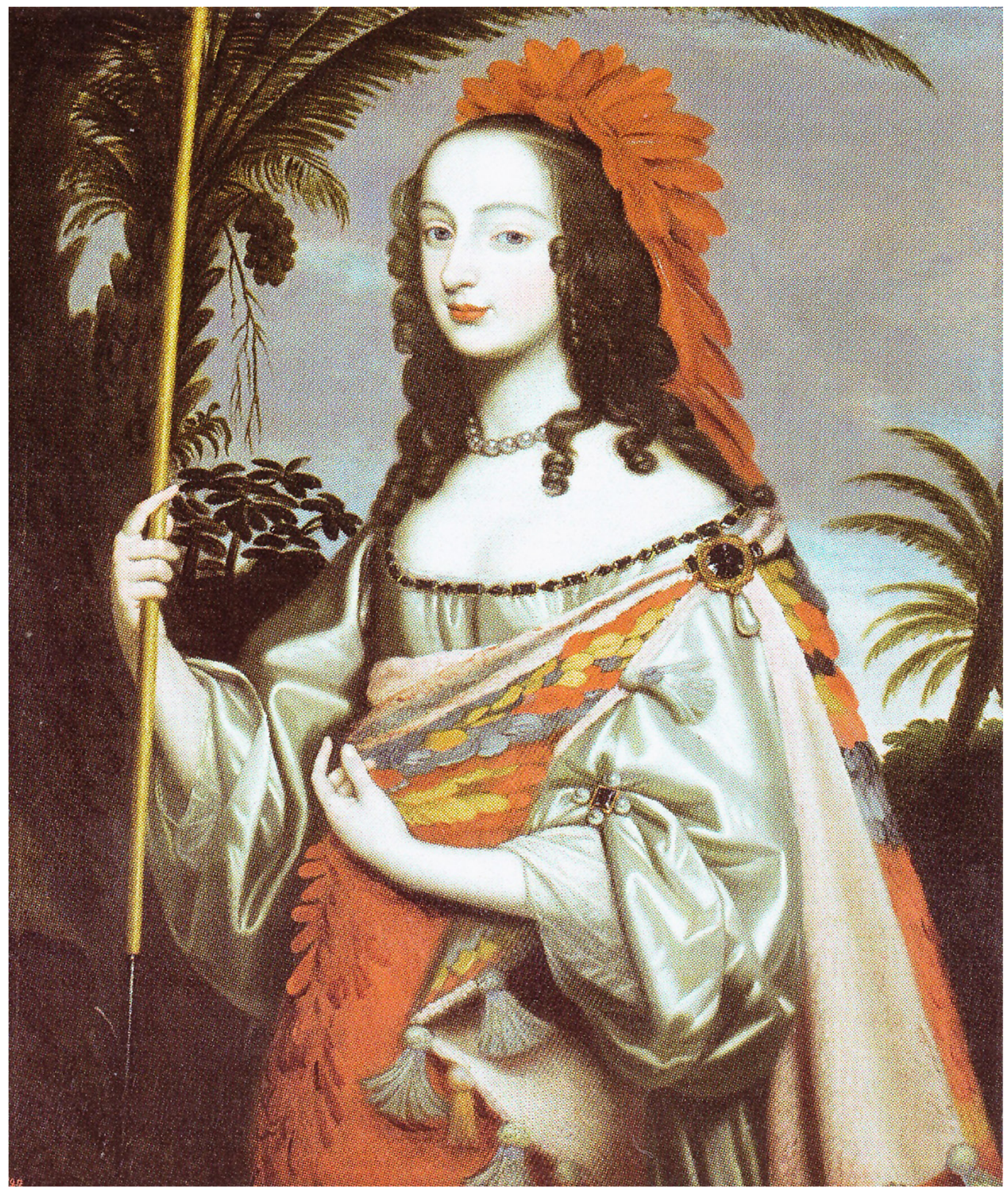

Figura 1 -Retrato de Sofia do Palatinado, de autoria por Lovise Hollandine do Palatinado,s. d., óleo sobre tela, $104 \times 86 \mathrm{~cm}$. Museu do Castelo de Wasserburg-Anholt, Isselburg, Alemanha. 
incomuns. Mas em geral elas "usavam turbantes ou máscaras, fantasiavam-se de personagens alegóricos ou mitológicos, ou ainda representavam um papel em peças teatrais dançantes ou balés da corte"7; elas não se valiam de adereços e objetos indígenas sul-americanos, então raríssimos na Europa. Não há nenhuma certeza sobre o contexto específico de produção desse quadro, que pode ter sido pintado em 1652, por ocasião do casamento de Guilherme Frederico e Albertina Agnes, ou até mesmo antes, em 1646, segundo uma especulação que o vincula ao matrimônio do eleitor de Brandemburgo com Louise Henriette van OrangeNassau. A ocasião pode ainda ter sido inteiramente corriqueira: Nassau teria simplesmente emprestado o manto para que Lovise retratasse a irmã. Em todo caso, ela não poderia ter pintado esse objeto em detalhes sem tê-lo visto pessoalmente, o que pressupõe a circulação do manto na corte de Haia nos dez anos subsequentes ao retorno de Nassau do Brasil. $\bigcirc$ significado dessa circulação não é contudo plenamente inteligível em si mesma: ela faz parte de um fenômeno muito mais amplo no tempo e no espaço.

Seiscentos foi um período de profundas mudanças para os Países Baixos, que conquistaram sua independência perante a Espanha, tornaram-se o centro comercial da Europa, consolidaram seu império colonial na Ásia e atacaram as colônias ibéricas na América e na África. A presença dos holandeses ao redor do mundo incentivou, como não poderia deixar de ser, a entrada de objetos e mercadorias oriundos de terras distantes nos Países Baixos, entre eles as especiarias, os espécimes naturais exógenos e os artefatos produzidos por populações não europeias, para citar apenas alguns. Ora, esses objetos e mercadorias não serviam apenas a uma finalidade prática; eles visavam também um propósito intelectual. Enquanto o açúcar, por exemplo, era consumido na alimentação, a cana de açúcar integrava as coleções de botânicos e naturalistas, indicando a diversidade do mundo vegetal. $\bigcirc$ interesse europeu por objetos artificiais e espécimes naturais raros remonta à ldade Média, mas a partir do século XVI, estimulado pela expansão ultramarina, assumiu, entre nobres e burgueses, um ímpeto verdadeiramente colecionista, dando origem às kunstkammers - "coleções de arte, de maravilhas, de raridades ou de curiosidades" 8 . Tais coleções desempenhavam igualmente uma função política, pois tanto a nobreza como a burguesia apreciavam exibi-las tendo em vista um duplo objetivo: de um lado, provocar o assombro de seus convidados, de outro, expressar algo sobre o próprio colecionador. Nesse sentido, as coleções de curiosidades, "embora privadas, só adquiriam significado na esfera pública, isto é, quando mostradas ou compartilhadas com outras pessoas. As coleções integravam e contribuíam diretamente para o acúmulo de capital simbólico do colecionador" ${ }^{\prime \prime}$. Mas essas coleções não eram formadas somente por meio de aquisições; elas dependiam também da troca de presentes que, ao mesmo tempo em que punha em movimento uma rede científica internacional de discussão e colaboração, fornecia uma dinâmica particularmente propícia às negociações e alianças propriamente políticas. Nesse caso, a ciência e a política não se encontravam portanto apartadas. Pelo contrário, o conhecimento ultramarino
7. Cf. Mariana de Campos Françozo (2014, p. 27).

8. Cf. Mariana de Campos Françozo (2014, p. 54).

9. Cf. Mariana de Campos Françozo (2014, p. 55). 
10. Cf. Mariana de Campos Françozo (2014, p. 28). assim acumulado pelos Países Baixos, que então concentravam a produção impressa europeia, possuindo as maiores taxas de alfabetizados e consequentemente o maior público leitor do continente, permitiu que os holandeses empreendessem de forma independente suas viagens de comércio e exploração. Foi justamente essa combinação engenhosa entre ciência e política que Nassau empregou com enorme competência, tanto em seu governo do Brasil Holandês como após seu retorno à Europa.

Nascido em 1604, Nassau recebera uma sólida formação humanista e acumulara uma ampla experiência militar, consagrada pela reconquista da cidade alemã de Schenkenschans das mãos dos espanhóis, quando a Companhia das Índias Ocidentais ofereceu-lhe, em 1636, o posto de governador-geral da colônia neerlandesa na América do Sul, uma posição prestigiosa e muito bem remunerada. Ao longo dos oito anos em que permaneceu no Brasil, Nassau desempenhou as obrigações políticas e militares exigidas por seu posto. Mas ele também desejava explorar a colônia do ponto de vista científico e artístico, produzindo um conjunto de textos e imagens capazes de descrever e registrar seus habitantes, sua fauna e sua flora, o que não havia sido realizado até então de forma meticulosa. No intuito de realizar tal projeto, o conde patrocinou a viagem e o trabalho dos pintores Albert Eckhout e Frans Post, do médico Willem Piso e do naturalista Georg Markgraf, para citar apenas os membros de seu entourage cuja presença efetiva no Brasil é considerada incontestável. Tal esforço, explica a autora,

se traduziu na criação de uma rica coleção que incluía espécies vegetais e animais; anotações, desenhos e aquarelas sobre a fauna e a flora do Brasil; pinturas a óleo - retratos e paisagens - da nova terra e, finalmente, artefatos confeccionados pelas mais diversas sociedades com as quais Nassau entrou em contato, direta ou indiretamente ${ }^{10}$.

Ainda que as aves e suas penas gozassem de centralidade no circuito de trocas entre os holandeses e seus aliados tapuias - e também entre os próprios indígenas, que, segundo os relatos do entourage de Nassau, valiam-se delas como ornamentos corporais -, arcos, flechas e outros artefatos percorriam igualmente um sentido nesse circuito, enquanto que no sentido contrário iam vestimentas de linho, miçangas e pregos, entre muitos outros objetos. Esse circuito não apenas constituía a aliança política entre o conde e os tapuias contra os portugueses; acima de tudo, ele garantia sua continuidade. Seria porém equivocado restringir tal circuito à relação entre Nassau e os indígenas da colônia holandesa em Pernambuco. Uma pia batismal de prata revestida em ouro, que se encontra hoje na lgreja Evangélica de Siegen, na Alemanha, assinala de modo particularmente eloquente a complexidade e a amplitude desse circuito. Em 1643, o conde recebeu-a da comitiva do rei do Congo, dom Garcia II, então aliado dos holandeses contra os portugueses na África. Tratava-se de uma aliança vital, pois daí provinha nada menos que o suprimento de escravos da colônia holandesa, sem os quais seu negócio açucareiro seria inviável. A origem da pia não era porém africana. Estima- 
se que ela fora talhada na região de Cusco, no final do Quinhentos, e mais tarde levada por portugueses mercadores de escravos até o rio da Prata, onde provavelmente fizera parte do pagamento por um lote de escravos, alcançando enfim o outro lado do Atlântico. Nassau por sua vez manteve-a em sua coleção durante quinze anos, até que, em 1658, levou-a consigo em uma viagem a Frankfurt para que o ourives Hans Georg Bauch acrescentasse-lhe o pé, revestissethe de ouro, adicionasse-the o brasão familiar do conde e uma inscrição assinalando que, tendo-a recebido do rei congolês durante seu governo da colônia holandesa no Brasil, ele oferecia-a agora de presente à Igreja Evangélica de Siegen.

Nassau preocupou-se também em patrocinar a produção de obras que representassem o Brasil aos olhos europeus, entre as quais se destaca a História natural do Brasil, redigida por Piso e Markgraf, editada por Johannes de Laet, então diretor da Companhia das Índias Ocidentais, e publicada em Amsterdã, em 1648. Essa obra teria um destino célebre, não apenas porque permaneceria pelos próximos 150 anos como a fonte privilegiada sobre os animais e as plantas brasileiros, mas também porque os nomes das espécies aí registrados serviriam parcialmente à formulação da taxonomia proposta por Carl Lineu na segunda metade do século XVIII, um passo decisivo para o conhecimento biológico. $\bigcirc$ sentido desse livro para o argumento de Mariana Françozo é todavia outro. De Laet encarregou-se de editar a História natural do Brasil porque Markgraf morrera em Angola por volta de 1644, mas tal tarefa não consistia simplesmente em transformar o manuscrito em livro:

(...) é preciso ter em mente que a adição de notas e imagens feitas por De Laet serviram para a finalidade prática de compor um livro o mais completo possível sobre a natureza do Brasil. A atividade editorial de De Laet também demonstra que a produção do conhecimento sobre - Novo Mundo era um processo coletivo e comparativo: os tratados publicados eram construídos através de compilações e comparações de diversas fontes. No caso da HNB, De Laet elaborou um compêndio com comparações entre a América Espanhola e a Portuguesa, e incluiu suas próprias opiniões e estudos da flora brasileira, sempre comparando o material de Markgraf com o que ele mesmo lera e vira. A História natural do Brasil é, portanto, produto exemplar da ampla circulação de saberes sobre o Novo Mundo que transcorria nos Países Baixos do século XVIII .

Ademais, a História natural do Brasil encerrava uma função prática: ainda que não fosse um manual para viajantes, ela "fornecia dados relevantes para a avaliação do potencial econômico de exploração daquela porção do Novo Mundo"12. Mais uma vez, a vontade de conhecer e a necessidade de explorar encontravam-se imbricadas.

Após o retorno de Nassau à Europa, sua coleção foi alojada em sua residência, a Mauritshuis, construída com pau-brasil e financiada com o dinheiro oriundo do açúcar. A Mauritshuis localiza-se no centro de Haia, próxima do Plein, o conjunto de edifícios que abrigava as reuniões dos Estados-Gerais desde o século $X V$, e portanto no qual transcorriam as principais atividades políticas holandesas. Não se trata, é claro, de uma posição fortuita. Ela representa estrategicamente no
11. Cf. Mariana de Campos Françozo (2014, p. 147).

12. Cf. Mariana de Campos Françozo (2014, p. 152). 
13. Cf. Mariana de Campos Françozo (2014, p. 175) espaço a ambição política de Nassau, que então precisava obter uma posição para si depois do serviço prestado no Brasil. Nesse sentido, sua coleção desempenhou uma função inestimável, pois consistia em "uma demonstração de conhecimento e de poder, um sinal distintivo que elevava a posição do colecionador dentro da sociedade altamente hierarquizada dos Países Baixos"13; ela forneceu ao conde um capital simbólico e um nome que poderiam ser convertidos em capital político, assegurando-the um status e uma condição material que não poderia obter por herança, visto que seu pai possuía poucas terras e muitos filhos. As recepç̃oes de Nassau em sua residência não se restringiam portanto ao mero entretenimento. Ao escolher cuidadosamente tanto seus convidados como os objetos de sua coleção que thes eram exibidos, ele dava provas públicas de sua habilidade a um só tempo como militar, governador e cortesão. Entrementes, ele também exibia sua coleção fora da Mauritshuis, em eventos e festas da corte, como no pomposo casamento de Albertina Agnes com Guilherme Frederico de Nassau-Dietz, que ocorreu em 1652 e incluiu encenações, bailes, música e torneios.

Da perspectiva prática, a aliança política mais vantajosa para Nassau foi a que logrou estabelecer com Frederico Guilherme, que, com a morte do pai em 1640, tornara-se duque da Prússia e eleitor de Brandemburgo, isto é, um dos responsáveis pela escolha do Sacro Imperador Romano-Germânico. Ambos se conheciam desde o sítio de Schenckenschans, no qual Nassau conquistara seu prestígio militar. Durante o período do conde em Pernambuco, não houvera porém contato entre ambos, situação que Nassau procurou reverter assim que retornou à Europa. Em contrapartida, o Brandemburgo possuía relações próximas com os Países Baixos e Nassau oferecia-the a possibilidade de estreitátlas ainda mais. Dessa maneira, em outubro de 1647, Nassau foi nomeado pelo Brandemburgo como stathouder de Cleve, Mark e Ravensberg, tornando-se responsável por governar e manter a paz nesse território próximo à fronteira dos Países Baixos. Em agradecimento, ele enviou-the um conjunto de manuscritos raros oriundos da biblioteca de seu pai. No início da década de 1650, a coleção brasiliana do conde ganhou fama e atraiu o interesse do Brandemburgo, presenteado afinal com objetos cuja característica mais saliente era a raridade: móveis decorados com detalhes em marfim esculpido, dentes de elefante, pinturas a óleo representando os indígenas e o mundo natural do Brasil, papéis contendo estudos de história natural, entre outros. Em contrapartida, Frederico Guilherme retribuiu-he com a propriedade de Freudenberg, a sudoeste de Cleve. Além da posição de stathouder, a aliança de Nassau com o Brandemburgo, na qual a troca de presentes desempenhou uma função decisiva, levou-o em 1652 a ser eleito grão-mestre da Ordem dos Cavaleiros de São João e, no ano seguinte, fez dele príncipe do império romano-germânico, sua consagração suprema; o conde inclusive representou o Brandemburgo na Dieta Imperial de Frankfurt, que elegeu em 1658 Leopoldo I da Áustria como imperador romano-germânico.

O significado pleno da presença do manto de penas tupinambá no retrato de Sofia do Palatinado reside assim na capacidade inestimável desse objeto 
exótico e absolutamente raro em conferir distinção, fosse para as duas irmãs, uma retratada, outra retratista, fosse para Nassau, o colecionador que o levara à Europa. Tal capacidade pressupõe a existência de um imenso interesse por esse tipo de objeto que, pautado certamente no apelo irresistível exercido pelo deslumbramento, era impelido igualmente por um objetivo intelectual que se imbricava de muitas maneiras, nesses tempos de mercantilismo, à necessidade de exploração comercial e de aliança política, instaurando um complexo circuito de trocas entre os dois lados do Atlântico. Nesse sentido, vale a pena ressaltar o caráter relacional desse circuito, evidentemente não apenas da perspectiva de Nassau, mas também de seus aliados tapuias, como bem mostra o exemplo do chefe Janduí, no Rio Grande, citado pela autora. $\bigcirc$ chefe explica a um emissário holandês que tinha necessidade de mais e melhores objetos, pois não apenas os exibia aos demais chefes como distribuía-os entre eles; do contrário, diz, ficaria só. Encontra-se em questão aqui a noção de dádiva, formulada, em 1925, por Marcel Mauss $^{14}$ : a obrigação de dar e retribuir presentes institui e fornece continuidade às relações sociais. Tal noção é fundamental para compreender o que a autora denomina a conexão holandesa:

No movimento de circulação de objetos etnográficos e espécies animais e vegetais entre as Índias Orientais e Ocidentais e a Europa, os Países Baixos tiveram um papel fundamental tanto na obtenção desses bens em suas terras de origem, no seu transporte até a Europa, na sua venda e distribuição através dos portos do norte europeu, quanto na própria apreciação, no interesse e na valorização de toda sorte de naturalia e artificialia. Homem de seu tempo, João Maurício de Nassau inseriu-se de forma perspicaz nessa dinâmica' ${ }^{15}$.

Nesse circuito de trocas global, Nassau não era evidentemente o único traficante do exótico, segundo o epíteto que the confere a autora. Mas sua habilidade ímpar em colocar, por assim dizer, esses objetos exóticos em movimento, obtendo vantagens políticas tanto na formação como na dispersão de sua coleção, faz dele um pivô importante desse circuito e, consequentemente, um ponto de acesso privilegiado para seu estudo. Dessa maneira, estabelecendo seu foco sobre Nassau e a temporalidade de sua coleção, De Olinda a Holanda consiste sem dúvida em uma contribuição inestimável ao conhecimento sobre a circulação de objetos, mercadorias, pessoas e saberes no Atlântico seiscentista. Mais que isso, trata-se igualmente de uma contribuição formidável ao diálogo entre a antropologia e a história, que se mostra mais uma vez bastante frutífero. Como antropóloga, Mariana Françozo é capaz de reconhecer o vínculo social profundo estabelecido pelos diversos tipos de trocas realizados por Nassau, uma vez que as trocas implicam sempre em reciprocidade, mesmo que desiguais. Mas a noção de dádiva de Mauss não é acionada por ela à custa das fontes históricas. Na verdade, é justamente seu domínio pleno dessas fontes que permite o emprego preciso de tal noção. Ao valer-se da ideia de dádiva para pensar tanto a relação dos tapuias com Nassau como a de Nassau com o Brandemburgo, entre outras tantas, a autora escapa de uma demarcação rígida entre ocidentais 
e não ocidentais sem cometer um abuso comum entre os antropólogos, que tendem a eleger frequentemente certas teorias oriundas de pesquisas etnográficas específicas como a medida de todas as coisas.

O rastreamento de um objeto etnográfico, e mesmo de uma coleção etnográfica inteira, exige portanto um exame minucioso do processo social e histórico que o ensejou, pois tal objeto circula de mão em mão, através de pessoas localizadas em posições sociais específicas e dirigidas por interesses particulares; através desse circuito, o próprio significado do objeto se transforma. Um estudo sobre o manto de plumas tupinambá do Trocadéro orientado por esses termos certamente iluminaria alguns trechos obscuros de sua trajetória, contribuindo assim com o esforço meticuloso de Métraux. Mas esse é apenas um exemplo entre os inúmeros objetos exóticos que compuseram coleções de maravilhas ao longo dos séculos e, para reconstituir suas trajetórias diversas, esse livro de Mariana Françozo servirá, sem dúvida, de modelo. 


\section{REFERÊNCIAS}

FRANÇOZO, Mariana de Campos. Um outro olhar: a etnologia alemã na obra de Sérgio Buarque de Holanda. 2004. Dissertação (Mestrado em Antropologia Social), Instituto de Filosofia e Ciências Humanas, Unicamp, Campinas, 2004.

LESTRINGANT, Frank. Le huguenot et le sauvage. L'Amérique et la controverse coloniale, en France, au temps des guerres de religion, Genebra: Librairie Droz, 2004.

MAUSS, Marcel. Ensaio sobre a dádiva. Forma e razão da troca nas sociedades arcaicas. In: 2003, p. 183-314. Sociologia e antropologia. Tradução de Paulo Neves. São Paulo: Cosac Naify,

MÉTRAUX, Alfred. À propos de deux objets tupinamba du Musée d'ethnographie du Trocadéro. Bulletin du Musée d'ethnographie du Trocadéro (Muséum national d'Histoire naturelle), $\mathrm{n}^{\circ} 3$, janeiro de 1932, pp. 3-18. Ed. fac-similar, Paris: Éditions Jean-Michel Place, 1988, pp. 95-110.

Artigo apresentado em 29/05/2016. Aprovado em 08/08/2016. 
